\title{
Protective Action of Luminal Bile Salts in Necrotizing Acute Pancreatitis in Mice
}

\author{
Guillermo Gomez, Courtney M. Townsend, Jr., Daniel W. Green, Srinivasan Rajaraman,* Tatsuo Uchida," \\ George H. Greeley, Jr., Roger D. Soloway,' and James C. Thompson \\ Department of Surgery, ${ }^{*}$ Department of Pathology, ${ }^{\S}$ Department of Medicine, and ${ }^{\ddagger}$ Office of Academic Computing and Biostatistics, \\ Department of Surgery, The University of Texas Medical Branch, Galveston, Texas 77550
}

\begin{abstract}
Bile salts in the intestinal lumen act to inhibit the release of cholecystokinin (CCK). Recent studies have shown that CCK may play a permissive role in the development of acute pancreatitis. In this study, the amount of luminal bile salts in female Swiss Webster mice was either decreased by feeding $4 \%$ (wt/ wt) cholestyramine or increased by feeding $0.5 \%$ sodium taurocholate for 1 wk. Plasma levels of CCK were stimulated by cholestyramine and inhibited by taurocholate. Then, acute pancreatitis was induced either by caerulein injections, or by feeding a choline-deficient, ethionine-supplemented (CDE) diet. Feeding of cholestyramine significantly decreased survival from $25 \%$ to $0 \%$ in the CDE pancreatitis, and increased the magnitude of elevation of serum amylase levels and the extent of pancreatic necrosis in both models of pancreatitis; CCK-receptor blockade with CR-1409 completely abolished the adverse effects of cholestyramine. In contrast, feeding of taurocholate significantly increased survival to $100 \%$ and decreased the elevation of serum amylase and pancreatic necrosis; CCK-8 antagonized these actions of taurocholate. Luminal bile salts appear to provide a physiologic protection against necrotizing pancreatitis, at least in part, both by inhibiting the release of $\mathrm{CCK}$ and by promoting resistance of the pancreas to CCK excessive stimulation in vivo. (J. Clin. Invest. 1990. 86:323-331.) Key words: bile salts • cholecystokinin • acute pancreatitis
\end{abstract}

\section{Introduction}

The mechanisms involved in the inception and progression of necrotizing acute pancreatitis are not completely understood. Calculous biliary tract disease is one of the processes most often associated with the development of acute pancreatitis (1), so-called biliary pancreatitis. Patients with biliary stone disease have been found to have a significant reduction of the size of the bile acids pool (2-4). Stones in the common bile duct, may additionally, of course, obstruct the normal flow of

Portions of this study were presented at the annual meeting of the American Pancreatic Association, Chicago, Illinois, October 28, 1988; and have been published in abstract form in 1988 (Pancreas. 3:597).

Address reprint requests to Courtney M. Townsend, Jr., M.D., Department of Surgery, The University of Texas Medical Branch, Galveston, TX 77550 .

Guillermo Gomez is a visiting scientist from the Department of Gastroenterology, Pontificia Universidad Catolica de Chile, Santiago, Chile.

Received for publication 3 April 1989 and in revised form 21 November 1989.

J. Clin. Invest.

(C) The American Society for Clinical Investigation, Inc.

0021-9738/90/07/0323/09 \$2.00

Volume 86, July 1990, 323-331 bile to the duodenum. Thus, the postprandial concentration of bile salts in the intestinal lumen may be expected to be diminished in patients with biliary stones.

We have recently shown that the secretion of bile salts into the intestinal lumen exerts a physiologic negative-feedback control on the release of cholecystokinin $(\mathrm{CCK})^{1}$ in dogs, guinea pigs, and humans $(5,6)$. Primary actions of the hormone CCK are the stimulation of pancreatic protein secretion and growth. The inhibition of CCK release induced by bile salts is paralleled by a potent inhibition of pancreatic protein secretion (5). Recent studies have suggested that CCK may play a contributory role in acute pancreatitis. The administration of CCK-receptor antagonists exerts a protective effect in several models of acute pancreatitis, such as those induced by caerulein $(7,8)$, choline-deficient, ethionine-supplemented (CDE) diet (9), or intrapancreatic injection of bile salts (10).

Based on these previous findings, we have postulated that a decreased amount of bile salts in the intestinal lumen may result in abnormally elevated levels of plasma CCK which, in turn, may play a role in the development or progression of pancreatitis. The present study was designed to determine the effect of luminal bile salts on the course of necrotizing acute pancreatitis in mice.

\section{Methods}

The following substances were purchased: taurocholic acid (synthetic sodium salt, $99 \%$ pure), cholestyramine resin and D,L-ethionine (Sigma Chemical Co., St. Louis, MO); chromatographically purified collagenase (CLSPA; Worthington Biochemicals, Freehold, NJ); octadecylsilylsilica (SEP-PAK C-18) cartridges (Waters Associates, Milford, MA); synthetic CCK-8-sulfate and caerulein (Bachem Inc., Torrance, CA). CCK-octapeptide (CCK-8) and cerulein were prepared at the desired concentration for injection in sterile physiologic saline solution for a final volume of $0.1 \mathrm{ml}$. Choline-deficient diet was obtained from Teklad (Madison, WI). The CCK-receptor antagonist, CR-1409 (i.e., D,L-4-(3,4 dicholobenzoylamine)-5-(dipentylamino)-5oxopentanoic acid), was kindly supplied by Professor Lucio Rovati of the Rotta Research Laboratory (Monza, Italy). CR-1409 was prepared freshly before administration at the desired concentration in physiologic saline solution for a final volume of $0.1 \mathrm{ml}$.

\section{Experimental design}

Young female Swiss Webster mice (Charles River Breeding Laboratories, Inc., Wilmington, MA) that were $\sim 5$ wk old and that weighed $\sim 14 \mathrm{~g}$ were used in this study. Mice were maintained in an environment of controlled temperature $\left(23^{\circ} \mathrm{C}\right)$, humidity, and lighting $(12 \mathrm{~h}$ light/12 h dark), with free access to tap water at all times.

The amount of endogenous bile salts in the intestinal lumen was chronically decreased by feeding a cholestyramine-supplemented $(4 \%$ $w t / w t)$ diet. Cholestyramine is an anion-exchange resin that binds bile salts in the intestinal lumen and effectively reduces the size of the bile

1. Abbreviations used in this paper: $\mathrm{CCK}$, cholecystokinin; $\mathrm{CDE}$, choline-deficient ethionine-supplemented. 
acids pool in a number of species (11) including the mouse (12). Because cholestyramine does not adsorb bile salts exclusively (13) we tested the effect of luminal bile salts on acute pancreatitis directly by feeding a taurocholate-supplemented $(0.5 \% \mathrm{wt} / \mathrm{wt})$ diet. A conjugated salt of cholic acid (sodium taurocholate) was used because the bile acids pool of mice is composed almost exclusively of cholic acid (12). The feeding of a $0.5 \%$ taurocholate-supplemented diet has shown to be highly efficient to increase both the pool size and the secretory rate of bile salts without affecting body weight in rodents (14). Blenderized regular chow (Purina Mills, Inc., St. Louis, MO) was used as control diet before and after the induction of pancreatitis.

Acute pancreatitis was induced by one of the following methods: by feeding a CDE diet ( $\leq 150$ parts per million of choline with a supplement of $0.5 \%$ ethionine) (9) or by injecting caerulein (7).

$C D E$ diet-induced pancreatitis. Separate groups of mice (the number of mice are given in the figures and tables) were fed either cholestyramine, taurocholate, or the control diet ad lib. for $1 \mathrm{wk}$ before induction of pancreatitis. The CDE diet was then given to the mice for $72 \mathrm{~h}$. Treatment with either cholestyramine or taurocholate was continued during and after the feeding of CDE diet until the completion of the observation period. Mice were followed for $192 \mathrm{~h}$ after the beginning of the CDE diet, and the rate of survival in each group was determined.

To examine the relationship between bile salts and CCK in pancreatitis, cholestyramine was also given in combination with the CCK-receptor antagonist, CR-1409 $(5 \mathrm{mg} / \mathrm{kg}$ per injection every $6 \mathrm{~h}$ subcutaneously), and taurocholate was also given in combination with CCK-8 ( $3 \mu \mathrm{g} / \mathrm{kg}$ per injection every $6 \mathrm{~h}$ subcutaneously); a second control group was given vehicle alone (saline, $0.1 \mathrm{ml} / \mathrm{h}$ every $6 \mathrm{~h}$ subcutaneously). At 0 time (before the CDE diet) and at $60 \mathrm{~h}$ on the CDE diet, 6-15 mice in each treatment group (excluded from the survival study) were sacrificed by decapitation for the collection of trunk blood and pancreatic tissue samples. Serum amylase levels were measured and pancreatic histology was analyzed as described below.

Because bile salts were found to be highly protective when given for $1 \mathrm{wk}$ before the induction of pancreatitis, another two groups of mice $(n=10)$ were given either the cholestyramine or taurocholate diets, this time beginning only $48 \mathrm{~h}$ before the CDE diet. These mice were observed exclusively for survival.

In a third set of experiments, we examined the reversibility of the effects of bile salts on CDE diet-induced pancreatitis (and pancreatic growth; see below). After 1 wk of treatment with the test diets (cholestyramine, taurocholate, or control), mice were placed on regular mouse chow for $4 \mathrm{wk}$. The CDE diet was then given for $72 \mathrm{~h}$ without the addition of cholestyramine or taurocholate.

Caerulein-induced pancreatitis. After 1 wk of treatment with either cholestyramine, taurocholate, or the control diet, acute pancreatitis was induced in another set of mice by means of intraperitoneal injections of caerulein $(50 \mu \mathrm{g} / \mathrm{kg}$ ) at hourly intervals for $8 \mathrm{~h}$ (nine injections). Mice were not fasted before the caerulein injections. At 8 or $12 \mathrm{~h}$ after the first injection of caerulein, 11-13 mice in each group were sacrificed as described before for the measurement of serum amylase and the analysis of pancreatic histology.

Concentration of bile salts in the intestinal lumen. After 1 wk of treatment with either cholestyramine, taurocholate, or control diet, 12 nonfasted mice from each group were sacrificed, the abdomen opened, and the duodenojejunal content was collected by gravity and gently stripping of the intestine. Duodenojejunal juice was separated from residual solids by centrifugation. Total intestinal bile salts were determined on $10 \mu \mathrm{l}$ of sonicated duodenojejunal juice either undiluted (samples from cholestyramine group) or in a 1:10 dilution with methanol (samples from the taurocholate or control groups) using the $3 \alpha-$ hydroxysteroid dehydrogenase assay (15).

Serum amylase and pancreatic histology. Serum was separated by centrifugation, and serum amylase levels were measured by the Phadebas Amylase Test $^{R}$ (Pharmacia Fine Chemicals, Piscataway, NJ). Histological examination was carried out by light and electron microscopy. Full-length sections (average of four) of pancreas of at least five mice per treatment group were examined blindly by the participating pathologist. For light microscopy, the tissues were fixed overnight in buffered formalin, processed, and embedded in paraffin; sections (4 $\mu \mathrm{m})$ were cut and stained with hematoxylin and eosin. For electron microscopy, tissue samples $\left(1 \mathrm{~mm}^{3}\right)$ were fixed in half-strength Karnovsky's fixative, postfixed in osmium tetroxide (1\%), and embedded in Epon; thin sections $(10 \mathrm{~nm})$ were stained with uranyl acetate and Reynold's lead citrate and were examined with a Philips 410 electron microscope.

Measurement of plasma $C C K$ and pancreatic growth. Nonfasted mice $(n=60)$ were killed between 0800 and 1000 hours by decapitation. Mixed arteriovenous trunk blood was collected in iced, heparinized tubes and plasma was separated by centrifugation. The plasma collected from six to seven mice in the same experimental group was pooled to prepare final plasma samples $(n=7-9)$ of $\sim 1.5 \mathrm{ml}$ each. At sacrifice, the pancreas from 18-20 mice in each treatment group were quickly harvested, trimmed of any fat, and weighed. In addition, the status of pancreatic growth was also studied $(n=10)$ after the 1-mo recovery period from the cholestyramine or taurocholate treatments.

Plasma levels of CCK in fed mice were measured using an in vitro bioassay as described by Liddle et al. (16). This bioassay measures specific plasma CCK bioactivity based on the release of amylase stimulated by plasma extracts from isolated rat pancreatic acini and it has been validated for mouse plasma (9). Plasma levels of CCK are expressed as CCK-8 equivalents in picomoles per liter.

Pancreas tissues were homogenized in five volumes by weight of saline. The concentrations of protein (17), DNA (18), and RNA (19) in the homogenates were measured by methods elsewhere described. Pancreatic protein, DNA, and RNA were calculated as the contents per entire pancreas.

\section{Statistical analysis}

Data from the measurements of intestinal bile salts concentrations, plasma CCK, or serum amylase levels, body, or pancreatic weights and the total contents of pancreatic protein, DNA, and RNA were analyzed by a one-way or two-way classification analysis of variance, where appropriate, and are shown as mean $\pm \mathrm{SE}$; the separation between means was done by the least significant difference procedure. Cumulative survival was plotted according to Kaplan and Meier (20). Survival data were analyzed using the Gehan-Wilcoxon test (21). Signifcance was assumed for $P<0.05$.

\section{Results}

The concentration of bile salts in the intestinal lumen of mice in the control group was $16.9 \pm 1.4 \mathrm{mM}$. The intestinal bile salts level rose significantly to $24.8 \pm 1.5 \mathrm{mM}$ with taurocholate treatment. In marked contrast, treatment of mice with cholestyramine for $1 \mathrm{wk}$ significantly reduced the concentration of intestinal bile salt to $0.05 \pm 0.005 \mathrm{mM}$.

All of the treatments given before the administration of CDE diet or caerulein were well tolerated by the mice. At this time period, histological examination carried out by light and electron microscopy showed no alterations of the pancreatic ductal, acinar, or islet-cell structure. There was no evidence of pancreatitis in any of the treatment groups. Similarly, no alterations of serum amylase levels were seen in either treatment group when compared to control values $(n=14$; $7.7 \pm 0.5 \mathrm{U} / \mathrm{ml})$.

$C D E$ diet-induced pancreatitis. Fig. 1 shows the serum amylase levels measured at $60 \mathrm{~h}$ on CDE diet in the mice that received the cholestyramine or taurocholate treatments beginning 1 wk before the induction of pancreatitis. Compared to the values at $0 \mathrm{~h}$ on the CDE diet, serum amylase levels rose significantly in all of the treatment groups. Treatment with cholestyramine, however, significantly increased the elevation 


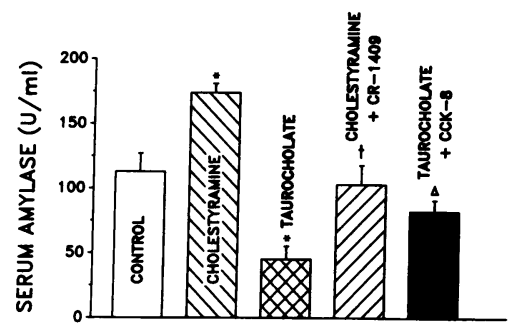

Figure 1. Serum amylase levels at $60 \mathrm{~h}$ on the CDE diet in mice. In these experiments all the treatments were given for $1 \mathrm{wk}$ before the CDE diet as described in Table $\mathrm{I}$, and were continued in the CDE diet until sacrifice. Control is CDE diet alone. Values are mean + SE of nine mice. Asterisk denotes different from control; dagger denotes different from cholestyramine alone; triangle denotes different from taurocholate alone.

of serum amylase levels by $54 \%$ when compared to control mice at $60 \mathrm{~h}$ on CDE diet; this enhancement effect of cholestyramine was completely abolished by the simultaneous administration of the CCK-receptor antagonist, CR-1409 (Fig 1). In contrast, treatment with taurocholate significantly decreased the elevation of serum amylase levels by $60 \%$ when compared to control mice at the same time period; this ameliorative effect of taurocholate was in turn significantly antagonized by the simultaneous administration of CCK-8 (Fig. 1).

Upon macroscopic examination of the opened abdomen at $60 \mathrm{~h}$ on CDE diet, there was obvious acute pancreatitis with pancreas grossly swollen and enlarged in all of the experimental groups. Extensive hemorrhagic infiltration of the pancreas and fat necrosis present in the omental tissues, mesentery, retroperitoneum, and pelvis were observed during treatment with cholestyramine. In striking contrast, intra-abdominal fat necrosis and hemorrhage were nearly absent during treatment with taurocholate. Mice in the control, cholestyramine plus CR-1409, or taurocholate plus CCK-8 groups exhibited a lesser degree of hemorrhage and fat necrosis than did mice treated with cholestyramine alone.

Results from the histological examination are summarized in Table I and Figs. 2-4. Basal cytoplasmic vacuolization of acinar cells or confluent areas of pancreatic necrosis (or both) were found in every treatment group. Necrosis and vacuolization affected a much larger proportion of the pancreas during treatment with cholestyramine; the simultaneous administration of CR-1409 markedly reduced the magnitude of pancre-

Table I. Pancreatic Histology in CDE Diet-induced Pancreatitis

\begin{tabular}{lcc}
\hline \multicolumn{1}{c}{ Treatment } & Percent vacuolization & Percent necrosis \\
\hline Control & 60 & 5 \\
Cholestyramine & 75 & 70 \\
Taurocholate & 10 & 0 \\
Cholestyramine + CR-1409 & 75 & 5 \\
Taurocholate + CCK-8 & 10 & $<5$ \\
\end{tabular}

The treatments were given to separate groups of mice from $1 \mathrm{wk}$ before the CDE diet. $4 \%$ (wt/wt) cholestyramine or $0.5 \%$ sodium taurocholate were given orally in food. CR-1409 $(5 \mathrm{mg} / \mathrm{kg})$ or CCK-8 (3 $\mu \mathrm{g} / \mathrm{kg}$ ) were given every $6 \mathrm{~h}$ subcutaneously. Pancreas tissue samples were collected at $60 \mathrm{~h}$ on CDE diet, fixed overnight in formalin, processed, and stained with hematoxylin and eosin. The pancreas from at least five mice per treatment group, were examined by light microscopy. Each pancreas was examined semiquantitatively at multiple levels (average of four levels of section), and $\sim 50$ high power $(400 \times)$ fields were examined in each level. atic necrosis compared with cholestyramine alone. By contrast, no necrosis and minimal vacuolization were observed during treatment with taurocholate, even when CCK-8 was simultaneously given.

The cumulative rates of survival from acute pancreatitis, when cholestyramine or taurocholate treatments were given from $1 \mathrm{wk}$ before the CDE diet, is shown in Fig. 5. The rate of survival in mice was not significantly affected by the administration of vehicle; $25 \%$ survival of control I group (without saline; Fig. 5, top) was virtually identical to the $22 \%$ survival of control II group (with saline; Fig. 5, bottom), so that the administration of saline $(0.1 \mathrm{ml}$ every $6 \mathrm{~h})$ was not a significant variable in these experiments. (A recent study by Niederau et al. [22] has shown that the administration of fluids can affect the course of CDE diet-induced pancreatitis in mice, but only if given in a volume of at least $6 \mathrm{ml} / \mathrm{d}$.) None of the mice treated with cholestyramine survived $(P<0.05$ vs. control; Fig. 5, top). In contrast, all $(100 \%)$ of mice during the taurocholate treatment survived ( $P<0.05$ vs. control; Fig. 5, top). The simultaneous administration of the CCK-receptor antagonist, CR-1409, completely abolished the adverse effect of cholestyramine on survival. The simultaneous administration of CCK-8 partially antagonized the protective effect of taurocholate on survival; $85 \%$ survival during treatment with CCK-8 (Fig. 5, bottom) was significantly smaller than the $100 \%$ survival of mice treated with taurocholate alone (Fig. 5, top), but was greater than that of controls.

When the treatment with cholestyramine or taurocholate was begun only $48 \mathrm{~h}$ before the induction of pancreatitis, survival of mice was $30 \%$ with cholestyramine and $70 \%$ with taurocholate. After a 1-mo recovery period from the test diets, neither serum amylase levels at $60 \mathrm{~h}$ on CDE diet $([\mathrm{U} / \mathrm{ml}]$, mean \pm SE of 10 mice, the control value was $109 \pm 11$; cholestyramine was $103 \pm 16$; taurocholate was $132 \pm 21$ ), nor the survival (control [ $n=24]$ was $42 \%$; cholestyramine [ $n=21$ ] was $34 \%$; taurocholate [ $n=24$ ] was $33 \%$ ) of mice were significantly different between the treatment groups. Thus, the effect of luminal bile salts on the course of CDE diet-induced pancreatitis was reversible with time.

Caerulein-induced pancreatitis. Serum amylase levels rose significantly in all the treatment groups after nine injections of caerulein (Fig. 6). $12 \mathrm{~h}$ after the first injection of cerulein, however, the elevation of serum amylase levels was significantly greater in the mice that were treated with cholestyramine (Fig. 6). In contrast, serum amylase levels at $8 \mathrm{~h}$ on cerulein were significantly lower in taurocholate-treated mice when compared to control and cholestyramine-treated mice (Fig. 6).

On macroscopic examination of the open abdomen, acute pancreatitis was evident in all of the treatment groups, but fat necrosis was absent in taurocholate-treated mice. By light microscopy, pancreatic inflammation and vacuolization of acinar cells were prominent features in all of the groups. However, the extent of necrosis was greater after treatment with cholestyramine and smaller after treatment with taurocholate (Table II).

Ultrastructural analysis of the pancreas in either model of pancreatitis (CDE diet or cerulein) revealed pancreatic acinar cell injury of varying intensity, depending on the areas chosen for examination. The totally necrotic cells exhibited shrunken nuclei with condensed nuclear chromatin or nuclei undergoing disruption and dissolution, degeneration of cellular organ- 


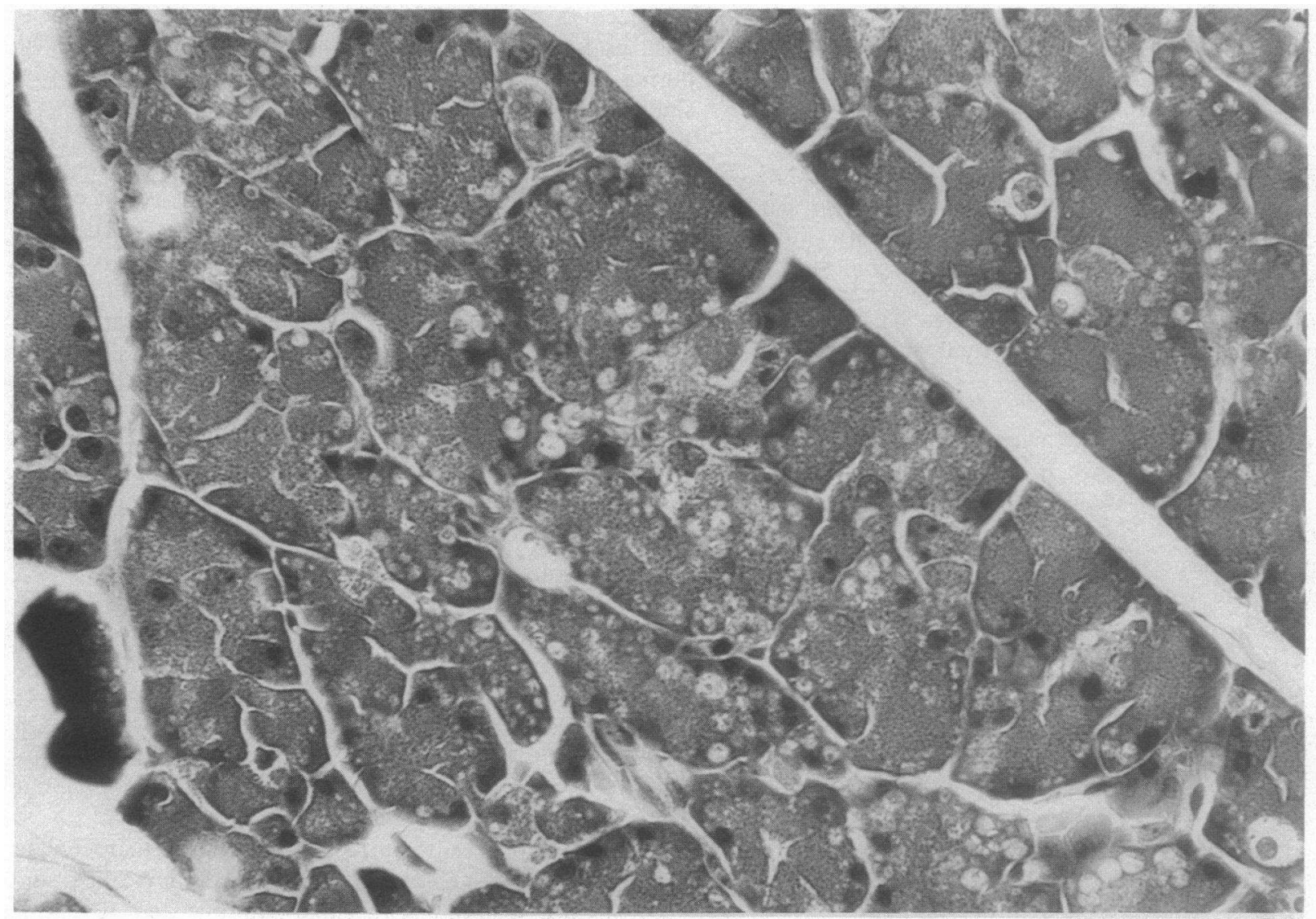

Figure 2. Photomicrograph of a representative section of pancreas at $60 \mathrm{~h}$ on CDE diet in control mice. Acinar cell necrosis and intracellular vacuolization are shown (250X). Histological examination as described in Table I.

elles, and multifocal disruption of cell membranes. Some other cells exhibited partial cytoplasmic degeneration with cytoplasmic vacuoles of varying sizes and shapes, which contained amorphous and flocculent debris. While many of the zymogen granules were intact, several others were in varying stages of degeneration such as loss of outer membrane and fragmentation and dissolution of granular substance. There was also degeneration of the endoplasmic reticulum in these foci.

Plasma CCK and pancreatic growth. The effect of feeding cholestyramine or taurocholate for 1 wk (before either the CDE diet or caerulein) on levels of food-stimulated plasma CCK is shown in Fig. 7. Compared to control values, cholestyramine significantly augmented CCK levels by $67 \%$, and taurocholate significantly decreased CCK levels by $50 \%$.

Feeding cholestyramine or taurocholate for $1 \mathrm{wk}$ did not influence the body weight $(n=60$; control $=17.9 \pm 0.2 \mathrm{~g}$; cholestyramine $=15.5 \pm 0.2 \mathrm{~g}$; taurocholate $=17.6 \pm 0.2 \mathrm{~g}$ ) or the weight gain in mice of any treatment group. Feeding $4 \%$ cholestyramine for $1 \mathrm{wk}$, however, caused pancreatic hypertrophy and hyperplasia. Cholestyramine significantly increased pancreatic weight by $33 \%$, and increased the total contents of protein by $19 \%$, DNA by $14 \%$, and RNA by $42 \%$ when compared to control values (Fig. 8). In contrast, feeding $0.5 \%$ taurocholate for $1 \mathrm{wk}$ inhibited all the measurements of pancreatic growth. Taurocholate significantly reduced pancreatic weight by $17 \%$, and decreased the total contents of protein by $24 \%$, DNA by $16 \%$, and RNA by $13 \%$ (Fig. 8 ).
After a 1-mo period of recovery from the test diets, pancreas in every treatment group were larger than their counterparts 1 mo before (data not shown). However, the differences in pancreatic growth between groups were no longer present 1 mo after the treatments with cholestyramine or taurocholate were discontinued. In the 1-mo recovery period, the pancreas weight increased by $88 \%$ in control, $44 \%$ in cholestyraminetreated, and $122 \%$ in taurocholate-treated mice. These increments in pancreas weight were paralleled by comparable increments in the total contents of pancreatic protein, DNA, and RNA. These results show that the changes in pancreatic growth (suppression by cholestyramine or stimulation by taurocholate) were halted after the treatments were discontinued, and the normal trophic steady-state of the pancreas was resumed. Thus, bile salts did not produce irreversible alterations of pancreatic growth.

\section{Discussion}

We have shown in this study for the first time that bile salts in the intestinal lumen exert a physiologic protection against severe, necrotizing acute pancreatitis. Chronic depletion of the pool of endogenous bile salts by feeding cholestyramine for 1 wk increased the magnitude of pancreatic destruction and maximally reduced survival of mice to zero in CDE diet-induced acute pancreatitis. Conversely, feeding the bile salt, taurocholate, for $1 \mathrm{wk}$ before pancreatitis greatly reduced the 


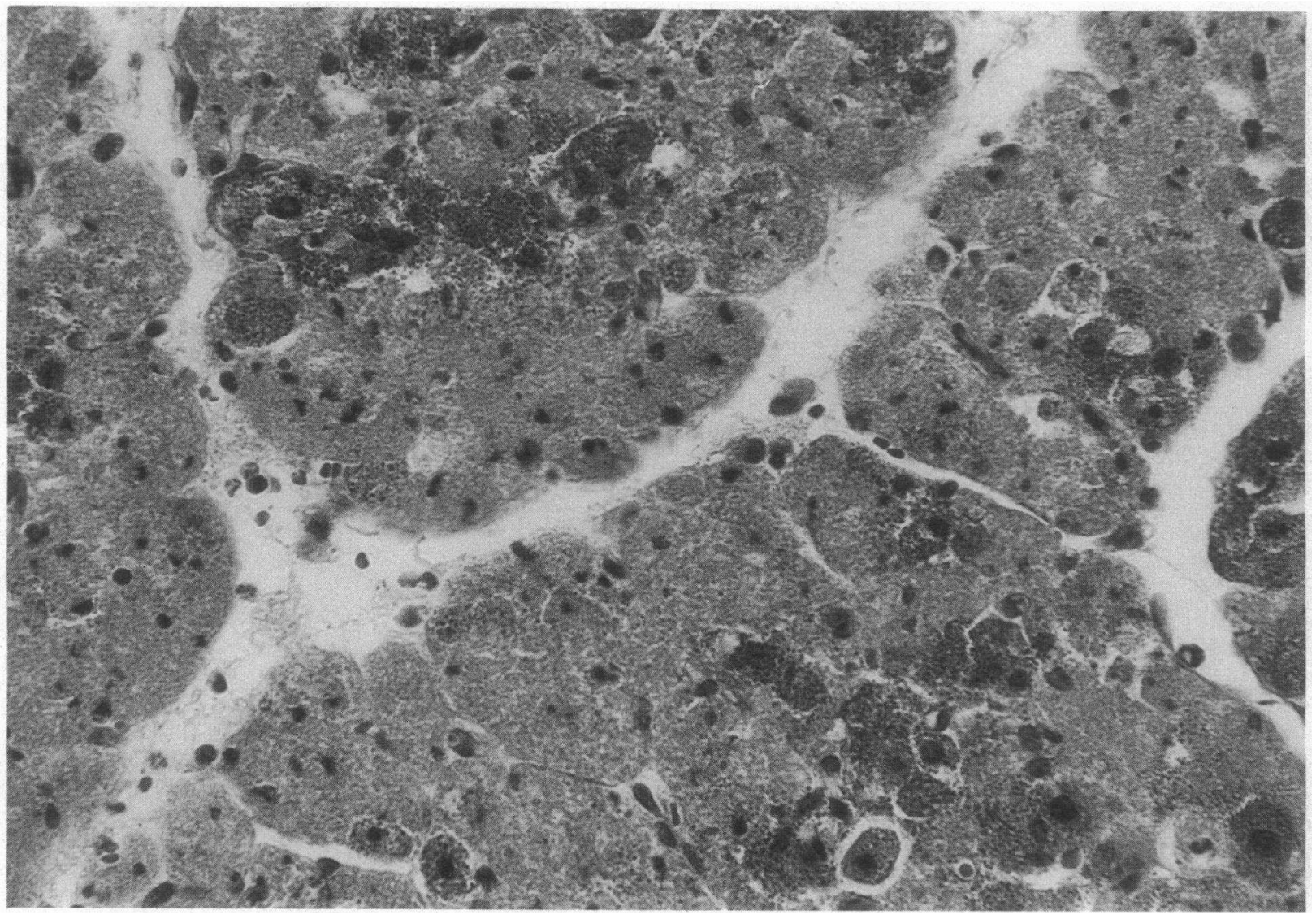

Figure 3. Photomicrograph of a representative section of pancreas at $60 \mathrm{~h}$ on CDE diet in mice which received cholestyramine from 1 wk before the CDE diet. More necrosis of acinar tissue and architectural disorganization compared to control mice (Fig. 2) are seen (250 $)$. Histological examination as described in Table $\mathrm{I}$.

magnitude of pancreatic cell damage, and completely abolished the mortality produced by the CDE diet. When the treatments with cholestyramine or taurocholate were instituted from $48 \mathrm{~h}$ only before the onset of the CDE diet, survival of mice was neither $0 \%$ with cholestyramine nor $100 \%$ with taurocholate. In related experiments (data not shown) we found that acute administration of larger amounts of bile salt (2.5\% taurocholate from the onset of the CDE diet) also failed to prevent mortality. These results suggest that a period of latency is required in order for bile salts to express their maximal effects on the course of acute pancreatitis. Alternatively, the size of the bile salts pool in mice is not sufficiently affected by $<1$ wk of oral treatment with cholestyramine or taurocholate at the doses tested. These findings indicate clearly, however, that taurocholate did not influence mortality simply by altering the physical properties of the CDE diet.

The mechanism by which luminal bile salts protect against necrotizing pancreatitis appears to be, at least in part, inhibition of endogenous release of CCK. The simultaneous administration of the CCK-receptor antagonist, CR-1409, completely abolished the deleterious effects of cholestyramine (which augments CCK release) on CDE diet-induced pancreatitis. Although CR-1409 could also interact with gastrin receptors in the pancreatic acinar cells (23), CR-1409 has a much higher affinity ( $>300$-fold) for the pancreatic CCK receptor than the gastrin receptor (23). In addition, we have shown previously that the exclusion of bile salts from the duodenum enhances meal-stimulated CCK, but not gastrin release (24).

CR-1409 at $5 \mathrm{mg} / \mathrm{kg}$ per $6 \mathrm{~h}$ plus cholestyramine did not improve CDE diet-induced pancreatitis per se (i.e., serum amylase levels and survival in mice treated with CR-1409 were not significantly different from control values). This result may be due exclusively to the dose of CR-1409 used. McQuaid et al. (25) have shown that CR-1409 at $10 \mathrm{mg} / \mathrm{kg}$ per $6 \mathrm{~h}$ significantly improves survival and decreases the elevation of serum amylase levels produced by CDE diet alone in mice. The present experiments were not designed to study the effect of CR-1409 on CDE diet-induced pancreatitis, that is, we did not perform a dose-response study. Instead, CR-1409 was used to show that the effect of lowering the amount of luminal bile salts on the course of pancreatitis was mediated by the release of endogenous CCK.

Accordingly, the simultaneous administration of exogenous CCK-8 significantly counteracted the protective effects of feeding taurocholate (which inhibits CCK release) on CDE diet-induced pancreatitis. The administration of CCK-8, however, did not completely abolish the improvement of survival produced by taurocholate. This observation suggests that inhibition of CCK release may not be the exclusive mechanism by which luminal bile salts could protect against necrotizing pancreatitis. The infusion of large amounts of bile or bile salts in 


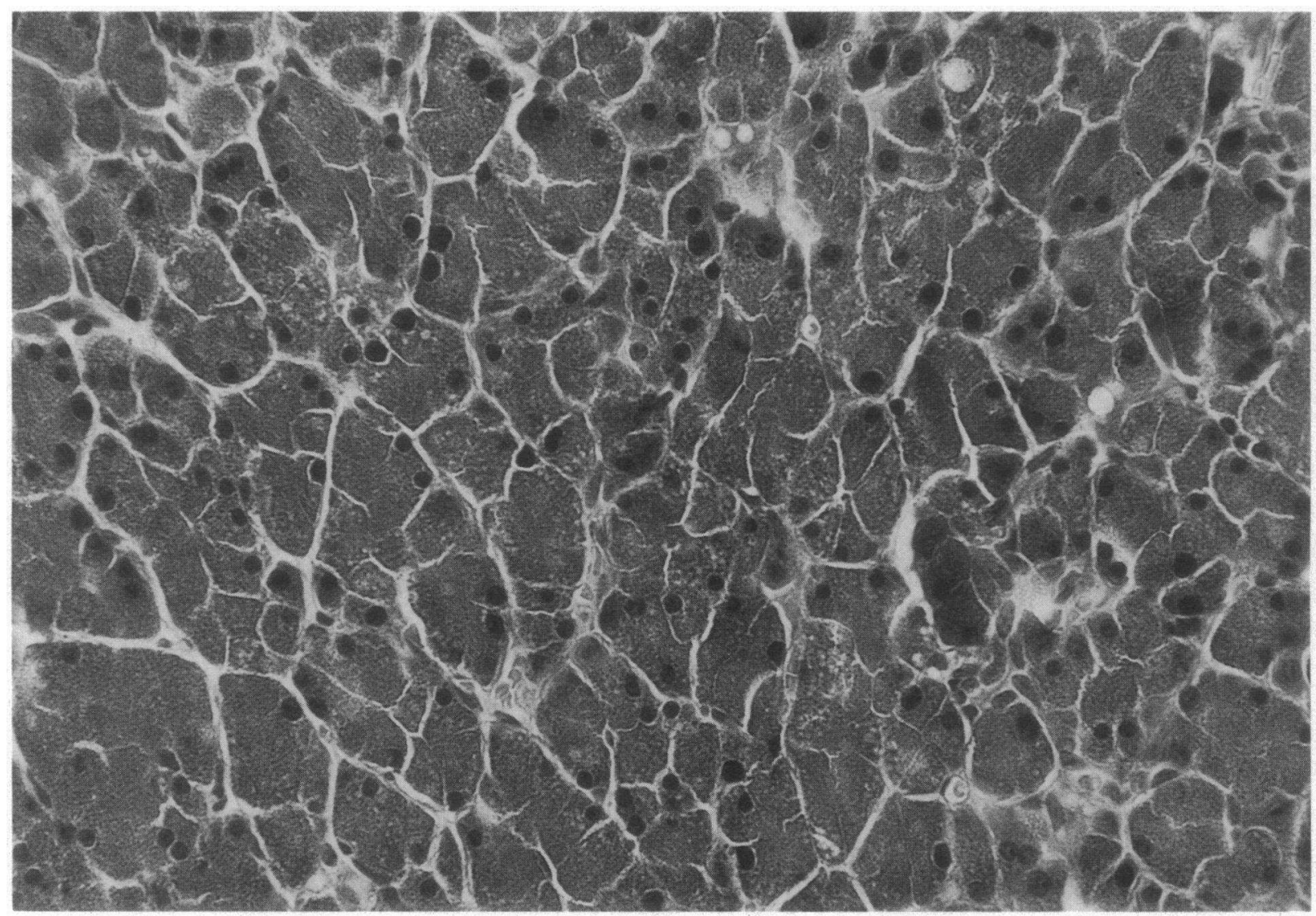

Figure 4. Photomicrograph of a representative section of pancreas at $60 \mathrm{~h}$ on CDE diet in mice which received taurocholate from 1 wk before the CDE diet. Architectural preservation of acinar tissue compared to control (Fig. 2) and no necrosis are seen (250X). Histological examination as described in Table $I$.

the duodenum has been shown to stimulate the release of other gut peptides such as secretin (26) and somatostatin (27). The studies by Renner and Wisner in rats (28) and dogs (29) and by Niederau et al. in mice (7) have shown that the administration of exogenous secretin can ameliorate the severity of pancreatitis induced by caerulein. The exogenous administration of somatostatin or the somatostatin analogue, SMS 201-995, was also found to be protective in pancreatitis induced by ligation of the distal bile duct in rats (30). Hypothetically, an increased release of secretin or somatostatin could also contribute to the beneficial effect of inhibiting CCK release by bile salts on acute pancreatitis.

The results obtained with the CDE diet model of pancreatitis suggested to us that chronic alterations in the amount of luminal bile salts could alter the in vivo resistance of the pancreas to injury from CCK stimulation. To test this hypothesis, we produced pancreatitis in mice by injecting the CCK analogue, caerulein. Pancreatitis induced by cerulein was more severe after chronic depletion of the bile salt pool, as determined by the greater elevation in serum amylase levels and more extensive pancreatic cell necrosis. Conversely, the chronic administration of taurocholate before caerulein had clear ameliorative effects. These differences in the severity of caerulein-induced pancreatitis could be due, in part, to a different total dose of secretagogue (i.e., caerulein plus endogenous (CK) in each treatment group. However, $50 \mu \mathrm{g} / \mathrm{kg}$ per injection is already a maximal dose of caerulein in this model of pancreatitis (7). Instead, these results suggest that the pancreas is more labile to suffer cell damage from hyperstimulation by CCK during a state of chronic deficiency of bile salts.

The relationship between bile salts and CCK release in mice was further demonstrated in this study by the simultaneous measurements of plasma CCK levels and pancreatic growth. Changes in pancreatic growth provided evidence for the physiologic significance of different levels of plasma CCK during the administration of either cholestyramine or taurocholate. We have previously demonstrated in dogs that the mechanism by which cholestyramine augments CCK release is the luminal neutralization of bile salts. We have discussed the mechanisms by which bile salts could inhibit the release of CCK (5).

Feeding cholestyramine for 1 wk augmented CCK release and caused pancreatic hypertrophy and hyperplasia in mice. Conversely, feeding taurocholate for $1 \mathrm{wk}$ inhibited both the release of CCK and pancreatic growth. Induction of pancreatitis after 1 wk of treatment with cholestyramine or taurocholate had diametrically opposite outcomes, depending on the treatment. Cholestyramine worsened and taurocholate ameliorated the severity of pancreatitis induced by both CDE diet or caerulein. We postulate, therefore, that the prognosis of pancreatitis is inversely related to the status of CCK release (and pancreatic stimulation) at the onset of acute pancreatitis. The 

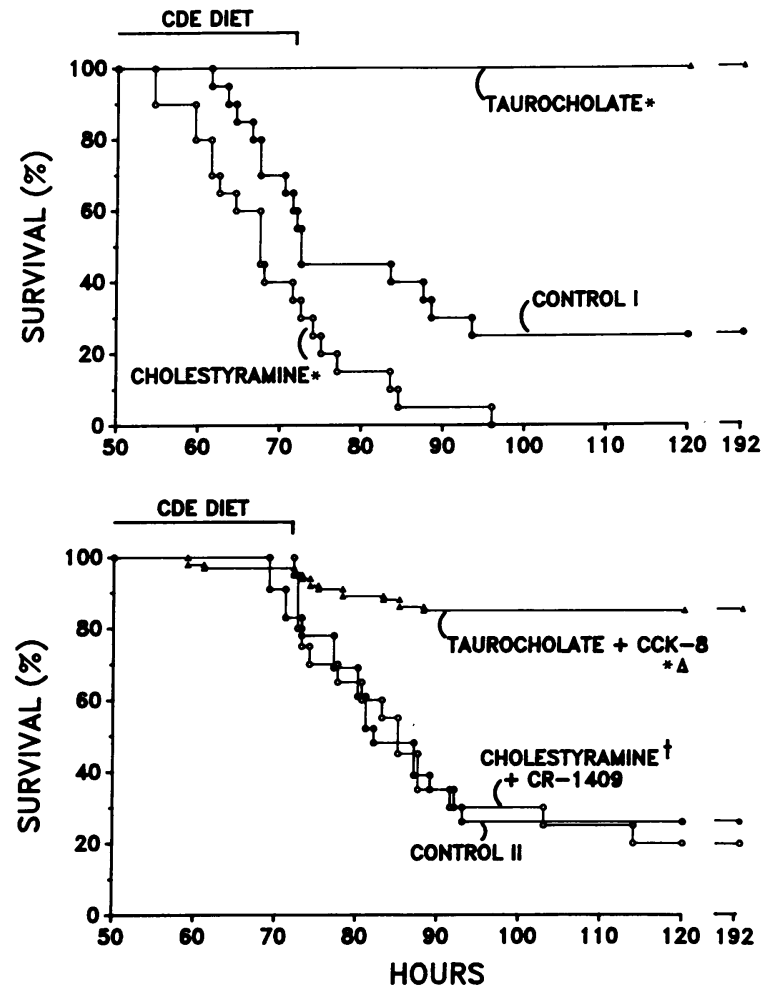

Figure 5. Cumulative survival. In these experiments all the treatments were given for 1 wk before the CDE diet, and were continued through the CDE diet until the completion of the observation period (192 h after the commencement of the CDE diet). The CDE diet was given for $72 \mathrm{~h}$. The treatments were given as described in Table I. Control II group received saline $(0.1 \mathrm{ml} / 6 \mathrm{~h}$, subcutaneously) and control I group did not. The initial number of mice are: (top) control $I=20$, cholestyramine $=20$, taurocholate $=40 ;($ bottom $)$, control II $=23$, cholestyramine plus CR-1409 $=20$, taurocholate plus CCK-8 $=65$. The meaning of symbols is described in Fig. 1 .

amount of bile salts in the intestinal lumen appears to be a major factor which can determine whether the course of pancreatitis is necrotizing and lethal, or mild and benign. In support of this hypothesis is the finding that alterations in the amount of luminal bile salts do not produce irreversible changes on the pancreas, at least for the periods of observation in these experiments. Discontinuation of either cholestyramine or taurocholate returned pancreatic growth to a normal steady-state; at this time, pancreatitis induced by CDE diet did not show any residual effects from the previous treatments with cholestyramine or taurocholate.

In a recent study Ohshio et al. (8) found that the potent CCK receptor antagonist, $\mathrm{L}-364,718$, had no effect in CDE

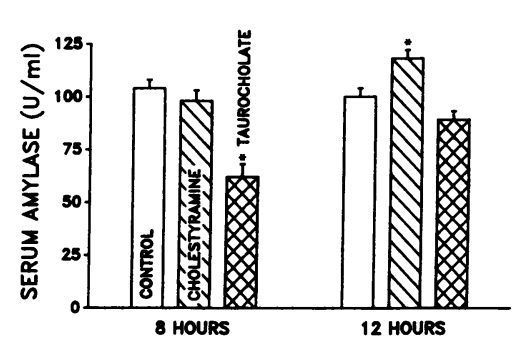

Figure 6. Serum amylase levels in mice during pancreatitis induced by caerulein. Same mice from experiments described in Table II. Values are mean + SE of 11-13 mice per group. Asterisk denotes different from control.
Table II. Pancreatic Necrosis (\%) in Caerulein-induced Pancreatitis

\begin{tabular}{lrl}
\hline \multicolumn{1}{c}{ Treatment } & $8 \mathrm{~h}$ & $12 \mathrm{~h}$ \\
\hline Control & 20 & 30 \\
Cholestyramine & 30 & 60 \\
Taurocholate & 5 & 25
\end{tabular}

The treatments were given as described in Table I. Without fasting, intraperitoneal injections of caerulein $(50 \mu \mathrm{g} / \mathrm{kg})$ were given at hourly intervals for $8 \mathrm{~h}$. Pancreas tissue samples were collected 8 and $12 \mathrm{~h}$ after the first injection of caerulein and examined by light microscopy as described in Table $I$.

diet-induced pancreatitis. Their study differed from ours as follows: there was no manipulation of release of endogenous CCK and mice were fasted for $24 \mathrm{~h}$ both before and after feeding the CDE diet. Under these experimental conditions one would expect that both plasma levels of CCK and pancreatic function would be in a basal state, therefore, very little effect on pancreatitis could be expected from the administration of L-364, 718. In contrast, they found that the course of caerulein-induced pancreatitis was significantly ameliorated by L-364, 718. Our data and those of Oshio et al. suggest that CCK receptor blockade may prove beneficial in the treatment of pancreatitis associated with elevated levels of plasma CCK.

The differences in mortality between groups could not be attributable simply to changes in pancreatic size. The histological examination of the pancreas during pancreatitis does not support this possibility. For comparable amounts of pancreatic parenchyma, that is field by field of cross-sectional area examined, there were striking differences in the magnitude of cell damage and necrosis between the treatment groups. In addition, there was no parallelism between the magnitude of change in pancreas size and survival. In the most extreme situation, taurocholate treatment inhibited pancreas weight by $17 \%$ and DNA content by $16 \%$, (which means that taurocholate-treated mice still had more than $80 \%$ of the pancreas present at the onset of pancreatitis), but reduced mortality to $0 \%$.

We suggest that this study may provide new insights into the possible mechanisms responsible for the classical associa-

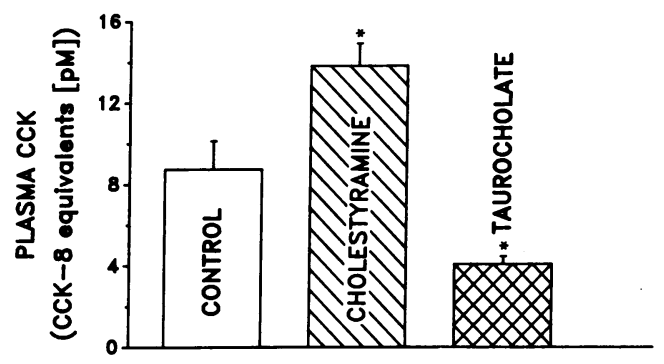

Figure 7. Effect of feeding either cholestyramine or taurocholate for 1 wk on food-stimulated plasma CCK levels in mice; control group received the regular mice food alone. CCK levels were measured by bioassay. For each determination, plasma collected from six to seven mice in the same experimental group was pooled and extracted. Values are mean + SE. Number of measurements are: control $=7$, cholestyramine $=9$, and taurocholate $=7$. Asterisk denotes different from control. 

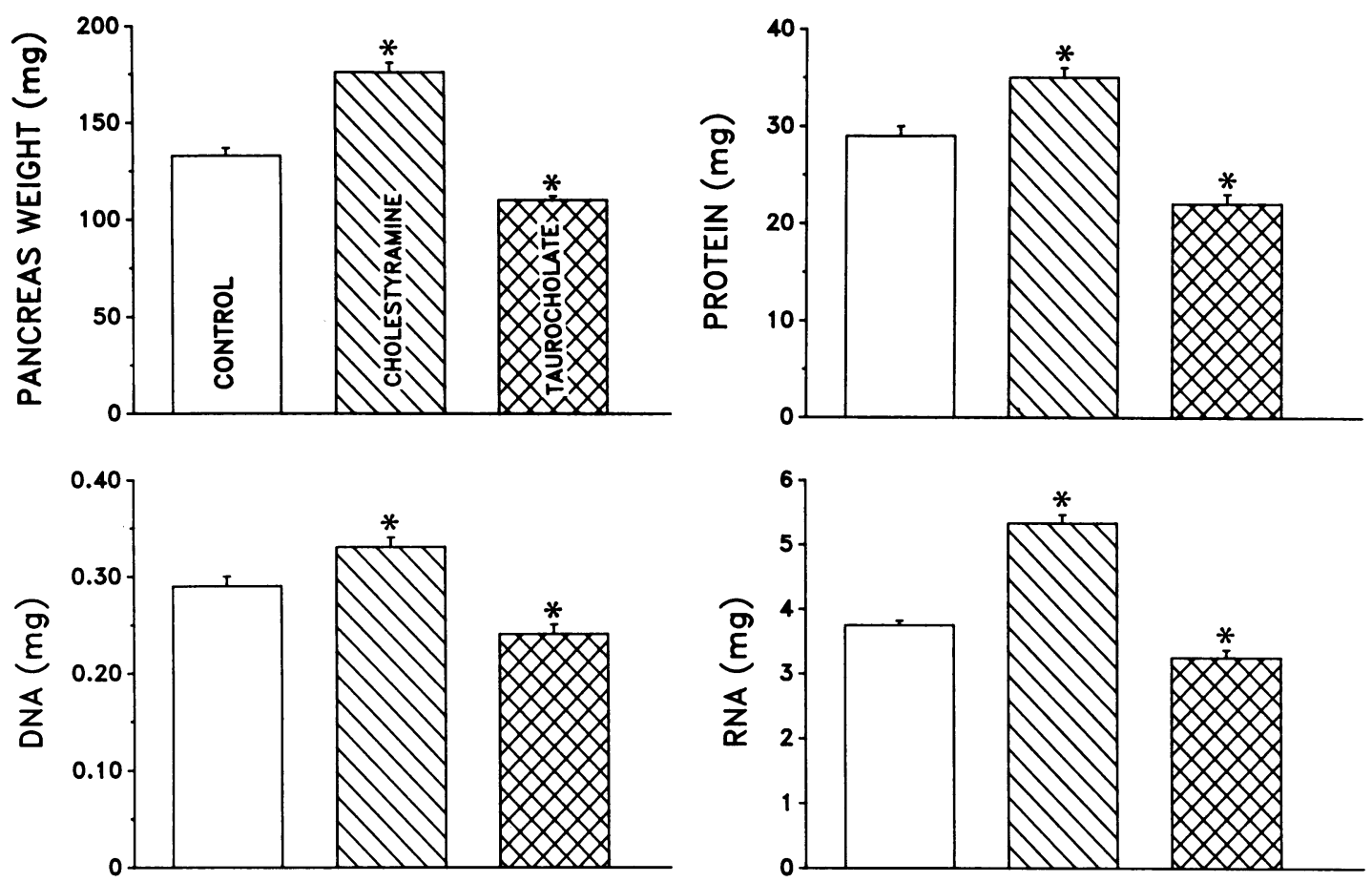

Figure 8. Pancreatic weight and total protein, DNA and RNA contents in mice after feeding either cholestyramine $(n=18)$, taurocholate $(n$ $=18)$, or control diet $(n=20)$ for $1 \mathrm{wk}$. Mice from the same experimental groups shown in Fig. 8 for plasma CCK levels. Values are means + SE. Asterisk denotes different from control.

tion between gallstone disease and the development of acute pancreatitis in humans. Several studies $(2,3,4)$ have demonstrated that patients with cholesterol gallstones suffer from a diminished bile salts pool (as much as $46 \%$ ) and a reduced output of bile salts into the duodenum (as measured by duodenal intubation techniques) in response to liquid diets. There is a direct relationship between the bile salts pool size and the bile salts secretion rate (3). In addition, obstruction of the common bile duct is the natural occurring complication of choledocholithiasis. Therefore, it seems that the act of a stone passing through the ampulla of Vater would invariably be accompanied by a significant reduction in the amount of bile salts into the duodenum. Recent studies in normal volunteers by Koop et al. (31) have shown that removal of bile salts with cholestyramine enhances both the release of CCK and pancreatic exocrine secretion stimulated by a liquid test meal.

In summary, we have demonstrated that bile salts in the intestinal lumen provide a physiologic protection against necrotizing acute pancreatitis in mice. This effect appears to involve, at least in part, inhibition of the release of CCK, the participation of pancreatic CCK receptors, and an increased resistance of the pancreas to CCK hyperstimulation in vivo.

\section{Acknowledgments}

Supported by grants from the National Institutes of Health (5R37 DK 15241, PO1 DK 35608) and by a grant from the American Cancer Society (PDT-220).

\section{References}

1. Steer, M. L. 1986. Etiology and pathophysiology of acute pancreatitis. In The Exocrine Pancreas: Biology, Pathobiology, and Diseases.
V. L. W. Go, F. P. Brooks, E. P. DiMagno, J. D. Gardner, E. Lebenthal, and G. A. Scheele, editors. Raven Press, New York. 465-474.

2. Vlahcevic, Z. R., C. C. Bell, Jr., I. Buhac, J. T. Farrar, and L. Swell. 1970. Diminished bile acid pool size in patients with gallstones. Gastroenterology. 59:165-173.

3. Shaffer, E. A., and D. M. Small. 1977. Biliary lipid secretion in cholesterol gallstone disease. The effect of cholecystectomy and obesity. J. Clin. Invest. 59:828-840.

4. Grundy, S. M., A. L. Metzger, and R. D. Adler. 1972. Mechanisms of lithogenic bile formation in american Indian women with cholesterol gallstones. J. Clin. Invest. 51:3026-3043.

5. Gomez, G., J. R. Upp, Jr., F. Lluis, R. W. Alexander, G. J. Poston, G. H. Greeley, Jr., and J. C. Thompson. 1988. Regulation of the release of cholecystokinin by bile salts in dogs and humans. Gastroenterology. 94:1036-1046.

6. Gomez, G., C. M. Townsend, Jr., R. Maani, P. Singh, G. H. Greeley, Jr., and J. C. Thompson. 1989. Down-regulation of pancreatic growth and gallbladder contractility by bile salts. Am. J. Surg. 157:20-26.

7. Niederau, C., L. D. Ferrell, and J. H. Grendell. 1985. Caeruleininduced acute necrotizing pancreatitis in mice: protective effects of proglumide, benzotript, and secretin. Gastroenterology. 88:11921204.

8. Ohshio, G., A. Saluja, U. Leli, A. Sengupta, and M. L. Steer. 1989. Failure of a potent cholecystokinin antagonist to protect against diet-induced pancreatitis in mice. Pancreas. 4:739-743.

9. Niederau, C., R. A. Liddle, L. D. Ferrell, and J. H. Grendell. 1986. Beneficial effects of cholecystokinin-receptor blockade and inhibition of proteolytic enzyme activity in experimental acute hemorrhagic pancreatitis in mice. Evidence for cholecystokinin as a major factor in the development of acute pancreatitis. J. Clin. Invest. 78:1056-1063.

10. Wisner, J. R., Jr., and I. G. Renner. 1988. Asperlicin, a nonpeptidal cholecystokinin receptor antagonist, attenuates sodium taurocholate-induced acute pancreatitis in rats. Pancreas. 3:174-179. 
11. Grundy, S. M. 1972. Treatment of hypercholesterolemia by interference with bile acid metabolism. Arch. Intern. Med. 130:638648.

12. Beher, W. T., M. E. Beher, and B. Rao. 1966. Bile acid and cholesterol metabolism in the mouse as affected by cholestyramine. Proc. Soc. Exp. Biol. Med. 122:881-884.

13. Johns, W. H., and T. R. Bates. 1969. Quantification of the binding tendencies of cholestyramine I: effect of structure and added electrolytes on the binding of unconjugated and conjugated bile-salts anions. J. Pharm. Sci. 58:179-183.

14. Stange, E. F., J. Scheibner, C. Lutz, and H. Ditzchuneit. 1988. Feedback regulation of bile acids synthesis in the rat by dietary vs. intravenous cholate or taurocholate. Hepatology. 8:879-886.

15. Turley, S. D., and J. M. Dietschy. 1978. Re-evaluation of the $3 \alpha$-hydroxysteroid dehydrogenase assay for total bile acids in bile. $J$. Lipid Res. 19:924-928.

16. Liddle, R. A., I. D. Goldfine, and J. A. Williams. 1984. Bioassay of plasma cholecystokinin in rats: effects of food, trypsin inhibitor, and alcohol. Gastroenterology. 87:542-549.

17. Lowry, O. H., N. J. Rosebrough, A. L. Farr, and R. J. Randall. 1951. Protein measurement with the Folin phenol reagent. J. Biol. Chem. 193:265-275.

18. Burton, K. 1956. A study of the conditions and mechanism of the diphenylamine reaction for the colorimetric estimation of deoxyribonucleic acid. Biochem. J. 62:315-323.

19. Dische, Z. 1953. Qualitative and quantitative colorimetric determination of heptoses. J. Biol. Chem. 204:983-997.

20. Kaplan, E. L., and P. Meier. 1958. Nonparametric estimation from incomplete observations. J. Am. Stat. Assoc. 53:457-481.

21. Gehan, E. A. 1965. A generalized Wilcoxon test for comparing arbitrarily singly-censored samples. Biometrika. 52:203-223.

22. Niederau, C., R. A. Crass, G. Silver, L. D. Ferrell, and J. H. Grendell. 1988. Therapeutic regimens in acute experimental hemorrhagic pancreatitis. Gastroenterology. 95:1648-1657.

23. Jensen, R. T., D.-H. Yu, and J. D. Gardner. 1988. Interaction of cholecystokinin antagonists with receptors on pancreatic acini. In Cholecystokinin Antagonists. Proceedings of a Workshop Held at the Banbury Center of Cold Spring Harbor, New York, September 21-22, 1987. R. Y. Wang and R. Schoenfeld, editors. Alan R. Liss, Inc., New York. 53-72.

24. Gomez, G., F. Lluis, J. Ishizuka, E. J. Draviam, T. Uchida, G. H. Greeley, Jr., and J. C. Thompson. 1987. Bile enhances release of insulin: an incretin-mediated effect. Surgery. 102:195-199.

25. McQuaid, K. R., C. Niederau, L. D. Ferrell, and J. H. Grendell. 1988. Effects of chlorglumide alone or with atropine or gastrin on diet-induced acute hemorrhagic pancreatitis in mice. Pancreas. 3:607. (Abstr)

26. Bondesen, S., H. Christensen, K. Lindorff-Larsen, and O. B. Schaffalitzky de Muckadell. 1985. Plasma secretin in response to pure bile salts and endogenous bile in man. Dig. Dis. Sci. 30:440-444.

27. Chayvialle, J.-A., M. Miyata, P. L. Rayford, and J. C. Thompson. 1980. Effects of test meal, intragastric nutrients, and intraduodenal bile on plasma concentrations of immunoreactive somatostatin and vasoactive intestinal peptide in dogs. Gastroenterology. 79:844852 .

28. Renner, I. G., J. R. Wisner, Jr., and H. Rinderknecht. 1983. Protective effects of exogenous secretin on ceruletide-induced acute pancreatitis in the rat. J. Clin. Invest. 72:1081-1092.

29. Renner, I. G., and J. R. Wisner, Jr. 1986. Ceruletide-induced acute pancreatitis in the dog and its amelioration by exogenous secretin. Int. J. Pancreatol. 1:39-49.

30. Baxter, J. N., S. A. Jenkins, D. W. Day, N. B. Roberts, D. C. Cowell, C. R. Mackie, and R. Shields. 1985. Effects of somatostatin and a long-acting somatostatin analogue on the prevention and treatment of experimentally induced acute pancreatitis in the rat. Br. J. Surg. 72:382-385.

31. Koop, I., A. Fellgiebel, H. Koop, A. Schafmayer, and R. Arnold. 1988. Effect of cholestyramine on plasma cholecystokinin and pancreatic polypeptide levels, and exocrine pancreatic secretion. Eur. J. Clin. Invest. 18:517-523. 